\title{
Neural processing of high and low spatial frequency information in faces changes across development: qualitative changes in face processing during adolescence
}

Citation for published version (APA):

Peters, J. C., Vlamings, P., \& Kemner, C. (2013). Neural processing of high and low spatial frequency information in faces changes across development: qualitative changes in face processing during adolescence. European Journal of Neuroscience, 37(9), 1448-1457. https://doi.org/10.1111/ejn.12172

Document status and date:

Published: 01/05/2013

DOI:

10.1111/ejn.12172

Document Version:

Publisher's PDF, also known as Version of record

Document license:

Taverne

Please check the document version of this publication:

- A submitted manuscript is the version of the article upon submission and before peer-review. There can be important differences between the submitted version and the official published version of record. People interested in the research are advised to contact the author for the final version of the publication, or visit the DOI to the publisher's website.

- The final author version and the galley proof are versions of the publication after peer review.

- The final published version features the final layout of the paper including the volume, issue and page numbers.

Link to publication

\footnotetext{
General rights rights.

- You may freely distribute the URL identifying the publication in the public portal. please follow below link for the End User Agreement:

www.umlib.nl/taverne-license

Take down policy

If you believe that this document breaches copyright please contact us at:

repository@maastrichtuniversity.nl

providing details and we will investigate your claim.
}

Copyright and moral rights for the publications made accessible in the public portal are retained by the authors and/or other copyright owners and it is a condition of accessing publications that users recognise and abide by the legal requirements associated with these

- Users may download and print one copy of any publication from the public portal for the purpose of private study or research.

- You may not further distribute the material or use it for any profit-making activity or commercial gain

If the publication is distributed under the terms of Article 25fa of the Dutch Copyright Act, indicated by the "Taverne" license above,

Download date: 26 Apr. 2023 


\title{
Neural processing of high and low spatial frequency information in faces changes across development: qualitative changes in face processing during adolescence
}

\author{
Judith C. Peters, ${ }^{1,2}$ Petra Vlamings ${ }^{2}$ and Chantal Kemner ${ }^{3,4}$ \\ ${ }^{1}$ Department of Neuroimaging and Neuromodeling, Netherlands Institute for Neuroscience, An institute of the Royal Netherlands \\ Academy of Arts and Sciences (KNAW), Meibergdreef 47, 1105 BA, Amsterdam, The Netherlands \\ ${ }^{2}$ Department of Cognitive Neuroscience, Faculty of Psychology and Neuroscience, Maastricht University, Maastricht, \\ The Netherlands \\ ${ }^{3}$ Department of Developmental Psychology, Utrecht University, Utrecht, The Netherlands \\ ${ }^{4}$ Department of Psychiatry, University Medical Centre, Utrecht, The Netherlands
}

Keywords: ERP, face processing, human, neurobiological development, spatial scales

\begin{abstract}
Face perception in adults depends on skilled processing of interattribute distances ('configural' processing), which is disrupted for faces presented in inverted orientation (face inversion effect or FIE). Children are not proficient in configural processing, and this might relate to an underlying immaturity to use facial information in low spatial frequency (SF) ranges, which capture the coarse information needed for configural processing. We hypothesized that during adolescence a shift from use of high to low SF information takes place. Therefore, we studied the influence of SF content on neural face processing in groups of children (910 years), adolescents (14-15 years) and young adults (21-29 years) by measuring event-related potentials (ERPs) to upright and inverted faces which varied in SF content. Results revealed that children show a neural FIE in early processing stages (i.e. P1; generated in early visual areas), suggesting a superficial, global facial analysis. In contrast, ERPs of adults revealed an FIE at later processing stages (i.e. N170; generated in face-selective, higher visual areas). Interestingly, adolescents showed FIEs in both processing stages, suggesting a hybrid developmental stage. Furthermore, adolescents and adults showed FIEs for stimuli containing low SF information, whereas such effects were driven by both low and high SF information in children. These results indicate that face processing has a protracted maturational course into adolescence, and is dependent on changes in SF processing. During adolescence, sensitivity to configural cues is developed, which aids the fast and holistic processing that is so special for faces.
\end{abstract}

\section{Introduction}

Faces are processed as a whole rather than as a collection of independent features (e.g. Sergent, 1984; Goffaux \& Rossion, 2006). This 'configural' processing (based on interattribute distances) is specific for faces, given that its disruption by presenting stimuli upside down strongly hampers the recognition of faces compared with other object types (the so-called 'face inversion effect' or FIE; Yin, 1969). It is unclear how this configural, global processing ability develops across childhood. Although newborns are already drawn toward faces, configural face processing skills develop relatively slowly until adulthood (e.g. Mondloch et al., 2002; CohenKadosh, 2011) and the FIE is not reliably shown across studies in children below 10 years (e.g. Carey \& Diamond, 1977; Schwarzer, 2000).

Correspondence: Dr J. C. Peters, ${ }^{1}$ Department of Neuroimaging and Neuromodeling, as above.

E-mail: j.peters@nin.knaw.nl

Received 15 September 2012, revised 15 January 2013, accepted 28 January 2013
This inadequate configural processing in children is reflected at the neural level by the lack of a neural FIE around 170 ms (N170 FIE) in the event-related potential (ERP), which only emerges from early adolescence on (Itier \& Taylor, 2002, 2004a). Instead, children show a neural FIE at the earliest cognitive processing stage (around $100 \mathrm{~ms}$; P1 FIE). In line with the weak behavioural FIE in children, this early neural FIE probably reflects a disruption of a superficial global analysis, akin to the holistic face processing observed in newborns (Farroni et al., 2000), rather than a disruption of the mature configural face processing based on interattribute distances (Taylor et al., 2004).

Importantly, these developmental changes in face processing might be influenced by coincidental changes in processing spatial frequency (SF) content of faces. Studies by Goffaux and colleagues (Goffaux et al., 2005; Goffaux \& Rossion, 2006) have provided evidence that configural face processing is mediated by low $(<8$ cycles-per-face-width or cpfw) SF (LSF), whereas local, feature information is extracted from high (>32 cpfw) SF (HSF; but see Gaspar et al., 2008; Willenbockel et al., 2010). Interestingly, 
Goffaux et al. (2003a) showed that in adults the N170 FIE effect is only shown when LSF information is present, which is in line with the hypothesis that global information is needed for configural processing of faces.

It is unclear whether the neural reflection of the FIE is also driven by LSF in children and adolescents. LSF and HSF are processed via different visual channels (De Valois \& De Valois, 1988) that mature at a different speed. Although LSF processing is present in newborns, sensitivity for LSF is only fully matured in preadolescence (9-12 years), much later than the maturation of HSF processing at 3-4 years (Adams \& Courage, 2002). The present ERP study examines the development of the role of SF on the neural FIE, by comparing neural responses in children, adolescents and adults to upright and inverted faces in which all SF information is available, or only in LSF or HSF ranges. In adults, we expect only an N170 FIE for faces containing LSF information (Goffaux et al., 2003b). In contrast, the P1 FIE in children (probing superficial processing) might not be affected by SF content. Finally, we expect a shift of superficial (i.e. SF-independent P1 FIE) to configural (LSF-dependent N170 FIE) processing during adolescence.

\section{Methods}

\section{Participants}

Healthy participants with (self-reported) normal or corrected-to-normal visual acuity were divided into three groups according to their age: children between 9 and 10 years $(n=20 ; 10$ males; median age $=10.2$ years; range 9.0-10.9 years), adolescents between 14 and 15 years $(n=20$; 7 males; median 15.0 years; range 14.0 15.8 years) and young adults (university students) between 21 and 29 years $(n=10 ; 5$ males; median age $=22.1$ years; range 21.3 29.2 years). Participants in these three groups were recruited from a primary school, high school and university in Zuid-Limburg (The Netherlands), respectively.

Each child and adolescent was in the normal cognitive range (i.e. IQ > 90) for their age, as assessed by the block design and vocabulary test of the WISC-III (Wechsler, 1991). Note that the estimated total IQ score derived from these subtests has a mean reliability of 0.94 and a mean validity of 0.91 compared with the complete WISC-III (Spreen \& Strauss, 1998). In addition, none of the children or adolescents had emotional or behavioural problems as indicated by scores on the Child Behaviour Checklist (Achenbach, 1991). Data of one adolescent were excluded due to technical problems. Participants (adolescents and adults) and parents (children and adolescents) gave their written informed consent to participate. All procedures were approved by the ethics committee of the Faculty of Psychology and Neuroscience of Maastricht University and were carried out in accordance with the European Communities Council Directive of 24 November 1986 (86/609/EEC) and the Code of Ethics of the World Medical Association (Declaration of Helsinki).

\section{Stimuli and task design}

Sixteen greyscale front-view photographs of Caucasian male $(n=8)$ and female $(n=8)$ faces with a neutral expression served as stimuli. Stimuli were selected from the NimStim Face Set (Tottenham et al., 2002) and trimmed to remove neck and hairline. Furthermore, all stimuli $\left(6.3^{\circ} \times 4.5^{\circ}\right)$ were equal in mean luminance $\left(48 \mathrm{~cd} / \mathrm{m}^{2}\right)$ and root mean square contrast (29) and were presented on a homogeneous grey background $\left(48 \mathrm{~cd} / \mathrm{m}^{2}\right)$. The SF content of each face was unfiltered (broad-pass SF or BSF), or filtered with a high-pass
(HSF; $\geq 6$ cycles/degree of visual angle $=27 \mathrm{cpfw}$ ) or low-pass (LSF; $\leq 2$ cycles/degree of visual angle $=9$ cpfw) cut-off. These cut-offs were chosen to exclude most of the intermediate frequencies (8-16 cpfw) necessary for adequate face recognition (Costen et al., 1994, 1996; Fiorentini et al., 1983; Gold et al., 1999), in line with our previous studies (Boeschoten et al., 2007; Vlamings et al., 2009) and those of Goffaux et al. (2003a). However, recent studies (Gaspar et al., 2008; Willenbockel et al., 2010) showed that information in the range of $6-10 \mathrm{cpfw}$ is also used for face recognition, which implies that LSF faces might be easier to recognize than HSF faces. However, because all faces were unfamiliar to the participants and the task (i.e. detection of animation) was unrelated to the face stimuli, face recognition effects are unlikely to influence ERP effects. Faces were presented in an upright or inverted $\left(180^{\circ}\right.$ rotation) orientation, resulting in six stimulus conditions as defined by SF content (BSF, LSF, HSF) and orientation (upright, inverted; Fig. 1). In addition, a seventh stimulus condition consisting of 16 different animation figures was included in the experiment to ensure subjects paid attention to the presented faces throughout the measurement. During the task, subjects were instructed to press a button as soon as an animation was shown on the screen. Stimuli from different conditions were randomly presented for $400 \mathrm{~ms}$ (except for animation figures, which were presented until response with a maximum of 4 s), with an interstimulus interval of $1100( \pm 200) \mathrm{ms}$.

Subjects were comfortably seated in front of a 21-inch LCD monitor (Dell Inc., Round Rock, TX, USA) (60-Hz refresh rate) in a dimly lit room. They were instructed to maintain a fixed viewing distance from the monitor and experimenters monitored this throughout the measurements. They received 96 randomized trials of each face stimulus condition (six repetitions of each stimulus). In addition, 48 trials of the animation stimulus condition were presented (three repetitions of each stimulus), resulting in 624 trials in total. These trials were divided into three blocks, in between which subjects rested for short periods. Participants were instructed to fixate on the middle of the screen and to press the button of a buttonbox as fast and as accurately as possible, when they detected a coloured animation.

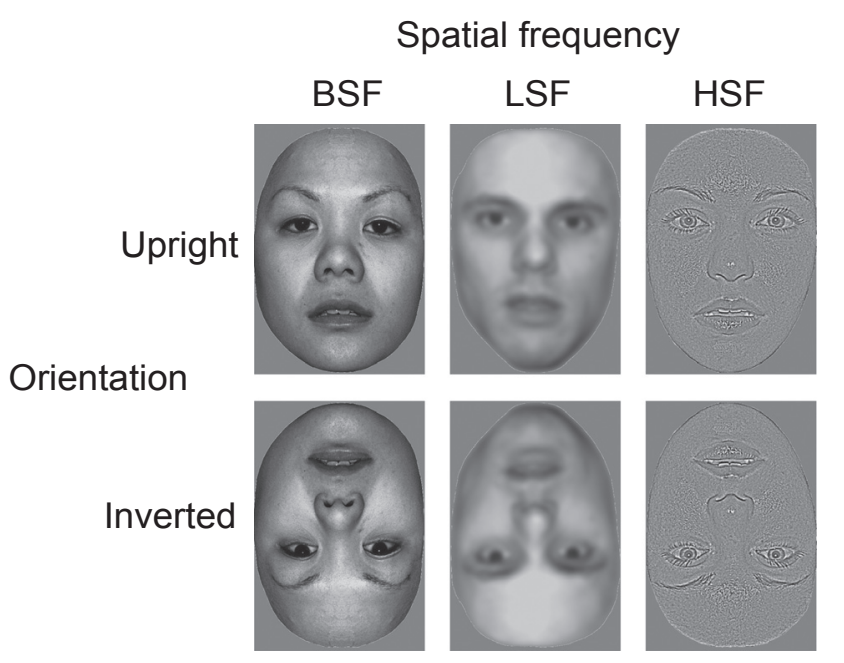

FIG. 1. Example of an unfiltered (BSF), low-pass filtered (LSF) and highpass filtered (HSF) face in upright (upper row) and inverted (lower row) orientation. As can be seen, coarse, global information can be extracted from images in which only the LSF range is preserved, whereas fine, local information is present in images with HSF content. In the unfiltered image (with broad-pass spatial frequencies or BSF), both types of information are present. 

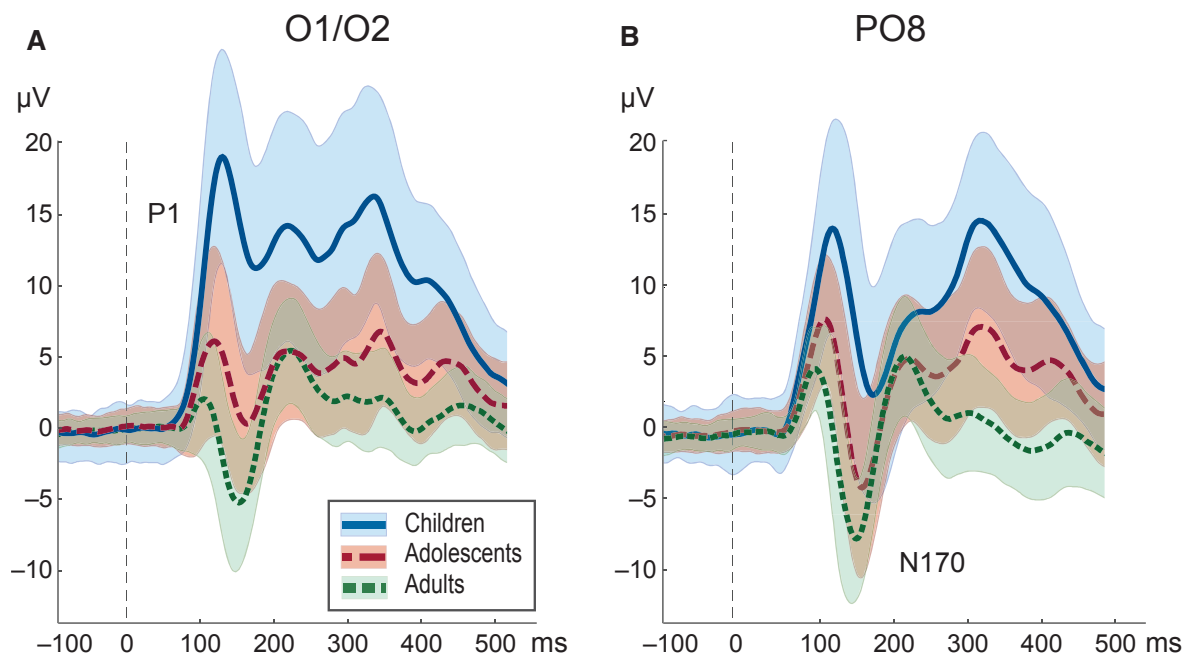

FIG. 2. Grand average waveforms of all conditions for children (9-10 years old), adolescents (14-15 years old) and young adults (21-30 years old) at electrodes (A) O1/O2 and (B) PO8. Note the large changes in ERP morphology across age groups. In this and subsequent figures, the shaded area indicates withingroup standard deviation.

\section{Electrophysiological recording and data analysis}

The electroencephalogram (EEG) was recorded (sampling rate $500 \mathrm{~Hz}$; band-pass filter of $0.01-200 \mathrm{~Hz}$; Brain Products amplifier, Munich, Germany) from $35 \mathrm{AgCl}$ scalp electrodes (extended International 10/20 system) with reference electrodes placed at the mastoids. Signals were collected using the left mastoid as reference and re-referenced off-line to the average activity of all electrodes. Horizontal and vertical electrooculograms (EOGs) were recorded with bipolar electrodes placed at the external canthii and above and below the left eye. Electrode impedance was kept below $20 \mathrm{k} \Omega$ for all electrodes.

EEG data were epoched $(-200$ to $600 \mathrm{~ms}$, relative to stimulus onset), band-pass filtered $(0.01-30 \mathrm{~Hz})$ and baseline corrected (200 ms pre-stimulus interval) using Vision Analyser (Brain Products $\mathrm{GmbH}$., Munich, Germany). Artefacts from horizontal eye movements and blinks were reduced with the algorithm of Gratton et al. (1983). Trials with artefacts (samples exceeding $\pm 75 \mu \mathrm{V}$ ) were excluded from subsequent analyses. The median number of trials per subject after artefact rejection of upright BSF, LSF, HSF and inverted BSF, LSF, HSF were 359 (min. 204 - max. 398), 299 (221 $-302), 312$ (210-437), 358 (284-367), 325 (187-397) and 316 (238
$-391)$, respectively. The median number of trials per subject did not depend on age group or condition (all $P>0.4$ ). As previous studies (e.g. Vlamings et al., 2010) showed that P1 influences might be displayed on different electrode sites across development, we analysed both $\mathrm{P} 1$ at occipital (O1, O2; Fig. 4) as well as at temporo-occipital (PO7, PO8; Fig. 5) electrodes. For each subject-specific averaged EEG epoch of a condition, latencies and amplitudes were automatically extracted at global peak-maximum at each individual channel in the P1 interval (100-190 ms for children and 70-160 ms for adolescents and adults) and N170 interval (140-240 ms for children and 130-200 ms for adolescents and adults). Peak amplitudes and latencies of the P1 and N170 were submitted to separate repeatedmeasures ANOVAs with Spatial Frequency (LSF, BSF, HSF), Orientation (upright, inverted) and Hemisphere (left, right) as within-subject factors and Age Group (children, adolescents, and adults) as between-subject factor. Results are Greenhouse-Geisser corrected when necessary. Note that main effects are not discussed when they interact with other factors. Instead, subsequently performed ANOVAS and/or paired $t$-tests are reported. Furthermore, effect sizes of reported effects were estimated using partial eta squared $\left(\eta^{2}\right)$. This is a standard metric in repeated-measure designs that estimates the magnitude of a given effect by quantifying the percentage of vari-
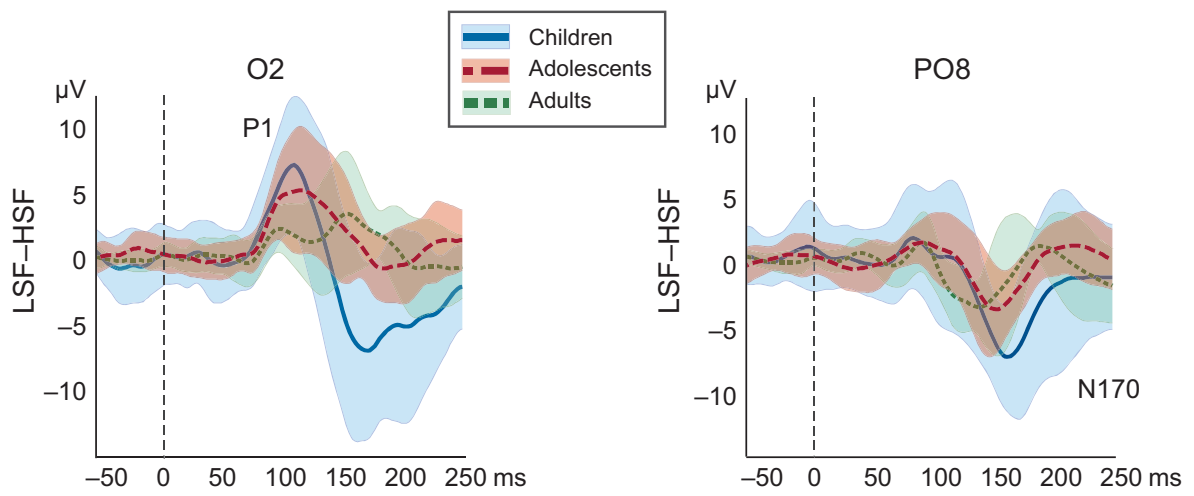

FIG. 3. Difference waves of low-pass (LSF) and high-pass (HSF) filtered faces at O2 and PO8 per age group. LSF faces elicit a faster and larger P1 and N170 than HSF faces, despite being equal in contrast and luminance. 
TABle 1 . Overview of the effects $(+, P<0.05 ;-, P>0.05)$ for $\mathrm{P} 1$ (upper part) and N170 (lower part) amplitude and latency from the repeated-measures ANOVAS with Spatial Frequency (SF), Face Orientation (ORI) and Hemisphere as within-subject factors and Age Group as between-subject factor; for clarity, main factors or interactions that are not significant in any of the groups are not shown, and significant main effects are not reported if they interact with one of the other factors

\begin{tabular}{|c|c|c|c|c|c|c|}
\hline & & Electrodes & Factor & $\begin{array}{l}\text { Effect } \\
\text { children }\end{array}$ & $\begin{array}{l}\text { Effect } \\
\text { adolescents }\end{array}$ & $\begin{array}{l}\text { Effect } \\
\text { adults }\end{array}$ \\
\hline \multirow[t]{7}{*}{ P1 } & Amplitude & $\mathrm{O} 1 \& \mathrm{O} 2$ & $\mathrm{SF}$ & - & + & + \\
\hline & & & ORI & + & + & - \\
\hline & & PO7 \& & SF & + & - & - \\
\hline & & PO8 & ORI & + & + & - \\
\hline & Latency & $\mathrm{O} 1 \& \mathrm{O} 2$ & $\mathrm{SF}$ & + & - & - \\
\hline & & PO7 \& & SF & + & + & $+*$ \\
\hline & & PO8 & ORI & + & + & - \\
\hline \multirow[t]{5}{*}{ N170 } & Amplitude & PO7 \& & $\mathrm{SF}$ & + & - & - \\
\hline & & PO8 & $\mathrm{ORI} \times \mathrm{SF}$ & - & + & + \\
\hline & & & Hemisphere & - & - & + \\
\hline & Latency & PO7 \& & $\mathrm{SF}$ & + & + & - \\
\hline & & PO8 & ORI $\times \mathrm{SF}$ & - & - & + \\
\hline
\end{tabular}

Observed effects per factor: SF, BSF and LSF faces had a higher amplitude/ shorter latency than HSF faces (*: effect was only observed for the right hemisphere); ORI, inverted faces had a higher amplitude/longer latency compared with upright faces; Hemisphere, higher N170 amplitude in the right than left hemisphere; ORI $\times \mathrm{SF}$, inverted faces had a higher amplitude/ longer latency compared with upright faces, but only for BSF and LSF faces.

ance explained by a given factor when excluding the contribution of inter-subject variance. Finally, inter-subject variability was assessed by plotting subject-specific peak amplitudes and latencies for the different estimated effects (see Figs. S1-S11).

\section{Results}

Subjects performed the detection task very well (accuracy $>95 \%$ ). Furthermore, there were no performance differences between age groups $(P=0.15)$.

\section{Age effects}

As can be seen in Fig. 2, the morphology of both the P1 as well as the N170 changes across development. Both the amplitude $\left(F_{2,46}=47.3, P<0.0001, \eta^{2}=0.67\right)$ and the latency $\left(F_{2,46}=41.3\right.$, $\left.P<0.0001, \eta^{2}=0.64\right)$ of the P1 at occipital sites decreased strongly with increasing age. All age groups differed significantly, indicating a continuous modification of the P1 across development. For the P1 at temporo-occipital sites, similar decreases were observed. Along the same line, the N170 amplitude became more negative with increasing age $\left(F_{2,46}=13.2, P<0.0001, \eta^{2}=0.36\right.$; note that the N170 peak has a positive sign in children), whereas latency $\left(F_{2,46}=13.7, P<0.0001, \eta^{2}=0.37\right)$ decreased.

\section{Spatial frequency effects}

Across age groups, we observed both faster as well as higher P1 and N170 peaks for LSF and BSF faces than for HSF faces (Fig. 3). This main effect of SF was influenced by age as well as face rotation, which will be further specified for each component in the sections below. An overview of the observed effects can be found in Table 1.

\section{P1 amplitude}

Occipital site $(\mathrm{O} 1, \mathrm{O} 2)$

Several interactions between P1 amplitude factors were significant (Fig. 4). There was an interaction between hemisphere and age group $\left(F_{2,46}=3.3, P=0.04, \eta^{2}=0.13\right)$ and between SF and age group $\left(F_{4,92}=3.4, P=0.02, \eta^{2}=0.13\right)$. Therefore we analysed results per group. Inverted faces elicited a higher P1 amplitude than upright faces in both children $\left(F_{1,19}=16.1, P=0.0008, \eta^{2}=0.46\right)$ and adolescents $\left(F_{1,18}=14.5, P=0.001, \eta^{2}=0.45\right)$. Furthermore, a main effect of SF was obtained for adolescents $\left(F_{2,36}=20.1\right.$, $\left.P<0.0001, \quad \eta^{2}=0.53\right) \quad$ and adults $\left(F_{2,18}=5.9, \quad P=0.01\right.$, $\eta^{2}=0.39$ ). In both groups, P1 amplitudes were larger for BSF (adolescents: $t_{18}=3.0, P=0.009$; adults: $t_{9}=3.4, P=0.08$ ) and LSF (adolescents: $t_{18}=5.1, P<0.0001$; adults: $t_{9}=2.7, P=0.02$ ) faces compared with HSF faces.

\section{Temporo-occipital site (PO7, PO8)}

The P1 amplitude at PO7 and PO8 showed similar effects to the P1 amplitude at occipital sites (Fig. 5). We analysed results per age group because there was an interaction between orientation and age group $\left(F_{2,46}=3.8, P=0.02, \eta^{2}=0.14\right)$ and between $\mathrm{SF}$ and age group $\left(F_{4,92}=4.9, P=0.02, \eta^{2}=0.18\right)$. Inverted faces elicited a higher P1 amplitude than upright faces in both children $\left(F_{1,19}=30.8, P<0.0001, \eta^{2}=0.62\right)$ and adolescents $\left(F_{1,18}=19.4\right.$, $\left.P=0.0003, \eta^{2}=0.52\right)$. Furthermore, a main effect of $\mathrm{SF}$ was obtained for children $\left(F_{1,19}=9.4, P=0.0005, \eta^{2}=0.33\right)$, with larger P1 amplitudes for BSF $\left(t_{19}=2.4, P=0.03\right)$ and $\operatorname{LSF}\left(t_{19}=3.7\right.$, $P=0.001)$ faces compared with HSF faces. In adults, the SF effect interacted weakly with orientation and hemisphere $\left(F_{2,18}=3.5\right.$, $P=0.05, \eta^{2}=0.28$ ), but none of the post hoc comparisons survived Bonferroni correction.

\section{P1 latency}

\section{Occipital site (O1, O2)}

Analyses on P1 peak latency revealed a three-way interaction between orientation, hemisphere and group $\left(F_{4,92}=4.3, P=0.02\right.$, $\left.\eta^{2}=0.16\right)$, as well as an interaction between SF and group $\left(F_{4,92}=9.3, \quad P<0.0001, \quad \eta^{2}=0.29\right)$. When analyses were performed per age group (Fig. 4), only a main effect of SF for children was observed $\left(F_{2,38}=17.5, P<0.0001, \eta^{2}=0.48\right)$. In this group, P1 latencies were shorter for $\operatorname{BSF}\left(t_{19}=2.3, P=0.03\right)$ and LSF $\left(t_{19}=7.7, P<0.0001\right)$ faces than for HSF faces.

\section{Temporo-occipital site (PO7, PO8)}

The P1 latency at PO7 and PO8 showed similar patterns to the latency of the occipital P1. We analysed results per age group because there was an interaction between hemisphere, SF and age group $\left(F_{4,92}=3.6, P=0.01, \eta^{2}=0.13\right)$ and between $\mathrm{SF}$ and group $\left(F_{4,92}=3.3, P=0.02, \eta^{2}=0.13\right)$. A main effect of SF for children $\left(F_{2,38}=29.2, \quad P<0.0001, \quad \eta^{2}=0.61\right)$, adolescents $\left(F_{2,36}=56.2\right.$, $\left.P<0.0001, \quad \eta^{2}=0.78\right)$ and adults $\left(F_{1,19}=7.9, \quad P=0.003\right.$, $\left.\eta^{2}=0.47\right)$ was observed. In adults, there was a significant interaction between SF and hemisphere $\left(F_{2,18}=5.5, P=0.04, \eta^{2}=0.38\right)$, as SF effects became only significant at PO8. P1 latencies were shorter for BSF faces (children: $t_{19}=5.0, P<0.0001$; adolescents: $t_{18}=11.0, P<0.0001 ;$ adults $\left.[\mathrm{PO} 8]: t_{9}=5.7, P=0.0003\right)$ and LSF faces (children: $t_{19}=7.3, P<0.0001$; adolescents: $t_{18}=8.1$, 

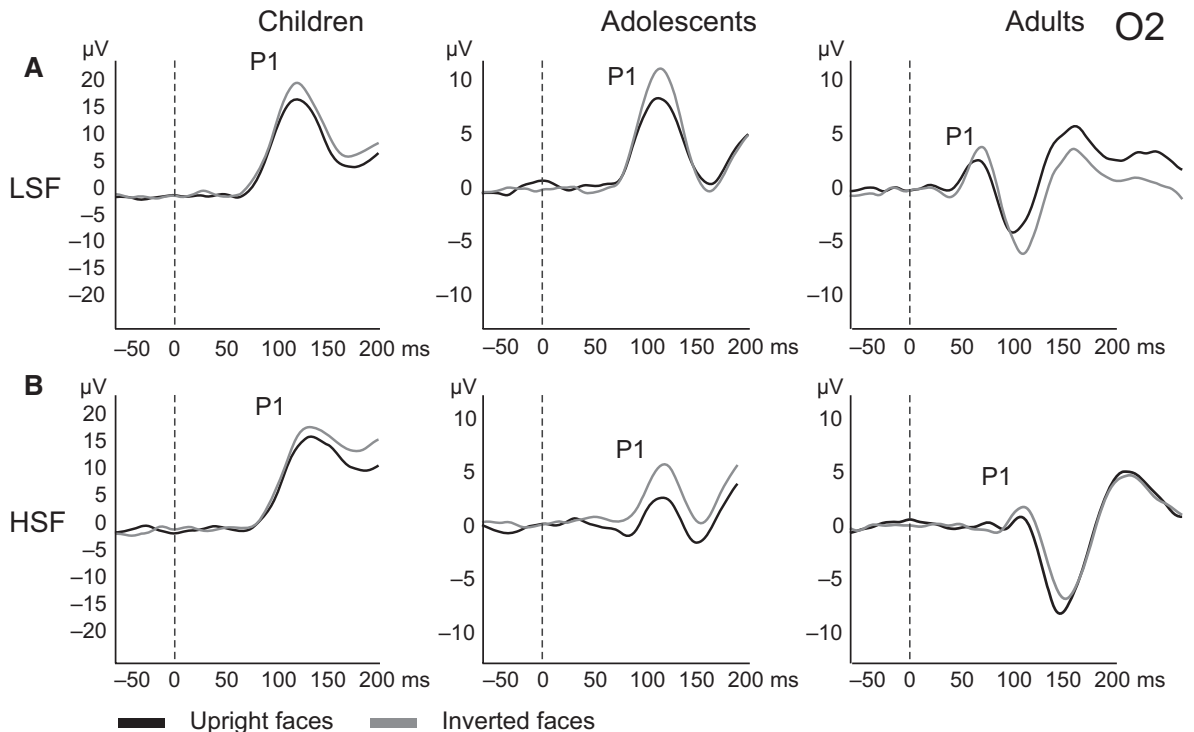

FIG. 4. Grand averages of upright and inverted faces at occipital electrode O2. P1 amplitudes are higher for inverted than for upright faces in the group of children and adolescents. This FIE is similar for (A) low-pass (LSF) and (B) high-pass (HSF) filtered faces. See Table 1 for further details. In this and following figures, we do not show the BSF waveforms for illustrative clarity, as the BSF waves largely overlap with the LSF waves.

A

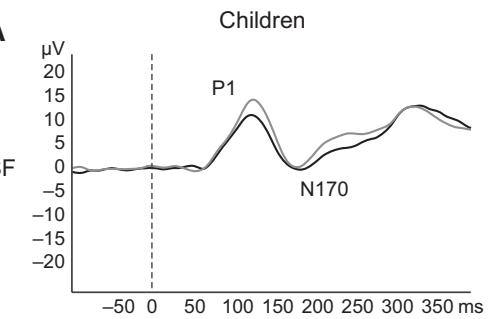

B

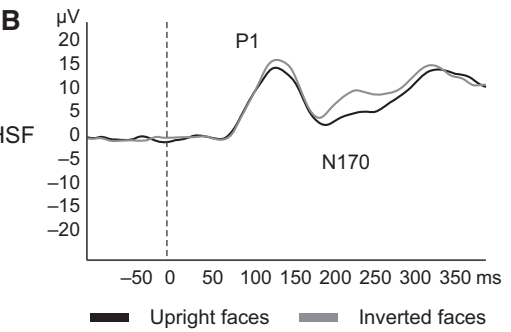

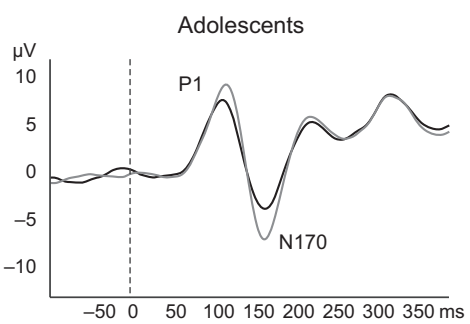
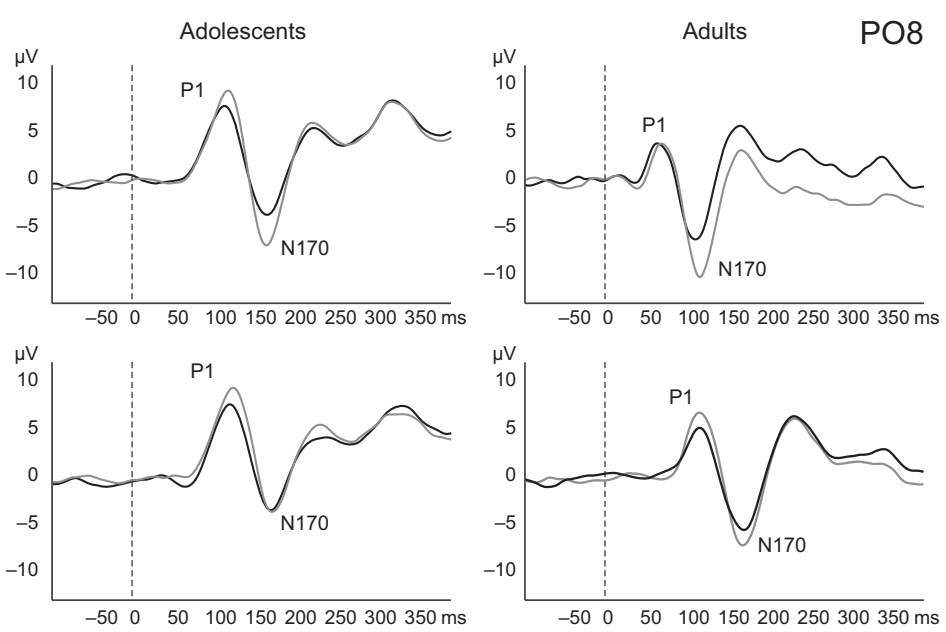

FIG. 5. Grand averages for children, adolescents and adults at right occipito-temporal electrode PO8. Similar to Fig. 4, children and adolescents (right and middle column) show a P1 FIE for (A) low-pass (LSF) and (B) high-pass (HSF) filtered faces. In contrast, only adolescents and adults (middle and left column) show an N170 FIE. Moreover, this FIE is only present when LSF information is available in the face (i.e. LSF and BSF faces). See Table 1 for further details.

$P<0.0001$; adults [PO8]: $\left.t_{9}=7.2, P<0.0001\right)$ than for HSF faces. Finally, children $\left(F_{1,19}=14.0, P=0.01, \eta^{2}=0.42\right)$ and adolescents $\left(F_{1,18}=12.8, P=0.002, \eta^{2}=0.42\right)$ showed a significant FIE, with delayed P1 latencies for inverted compared with upright faces.

\section{N170 amplitude}

There were significant interactions between orientation and group $\left(F_{2,46}=7.9, \quad P=0.01, \quad \eta^{2}=0.26\right), \quad$ between $\quad \mathrm{SF}$ and group $\left(F_{4,92}=5.5, P=0.001, \eta^{2}=0.19\right)$, and between orientation and SF $\left(F_{2,4}=6.1, P=0.04, \eta^{2}=0.12\right.$; Fig. 5). Children showed a main effect of $\operatorname{SF}\left(F_{2,38}=13.2, P=0.0002, \eta^{2}=0.41\right)$, with larger amplitudes for LSF $\left(t_{19}=5.0, P<0.0001\right)$ and BSF faces $\left(t_{19}=3.0, P=0.008\right)$ compared with HSF faces. They did not show an effect of orientation, or an interaction between orientation and SF. In contrast, orientation was influenced by SF in the group of adolescents $\left(F_{2,36}=9.4, \quad P=0.0005, \quad \eta^{2}=0.34\right)$ and adults $\left(F_{2,18}=4.6, \quad P<0.05, \quad \eta^{2}=0.34\right)$. As suggested by the grand averages for adolescents and adults, the N170 response was enhanced for inverted compared with upright faces, but only for LSF faces. This difference was confirmed by statistics: both adolescents and adults showed an FIE (i.e. higher amplitudes for inverted compared with upright faces) for BSF (adolescents: $t_{18}=4.0, P=0.01$; adults: $t_{9}=3.6, P=0.006$ ) and LSF (adolescents: $t_{18}=2.8, P=0.01$; adults: $t_{9}=3.4, P=0.008$ ) faces, but not for HSF faces (adolescents: $t_{18}=0.4, P=0.7$; adults: $t_{9}=1.3$, $P=0.2$ ). Finally, orientation interacted with hemisphere in adolescents $\left(F_{1,18}=7.1, P=0.02, \eta^{2}=0.28\right)$, as inverted faces elicited a higher amplitude at PO8 $\left(t_{18}=3.0, P=0.01\right)$, but not at PO7 $(P=0.4)$. In adults, there was a main effect of hemisphere 

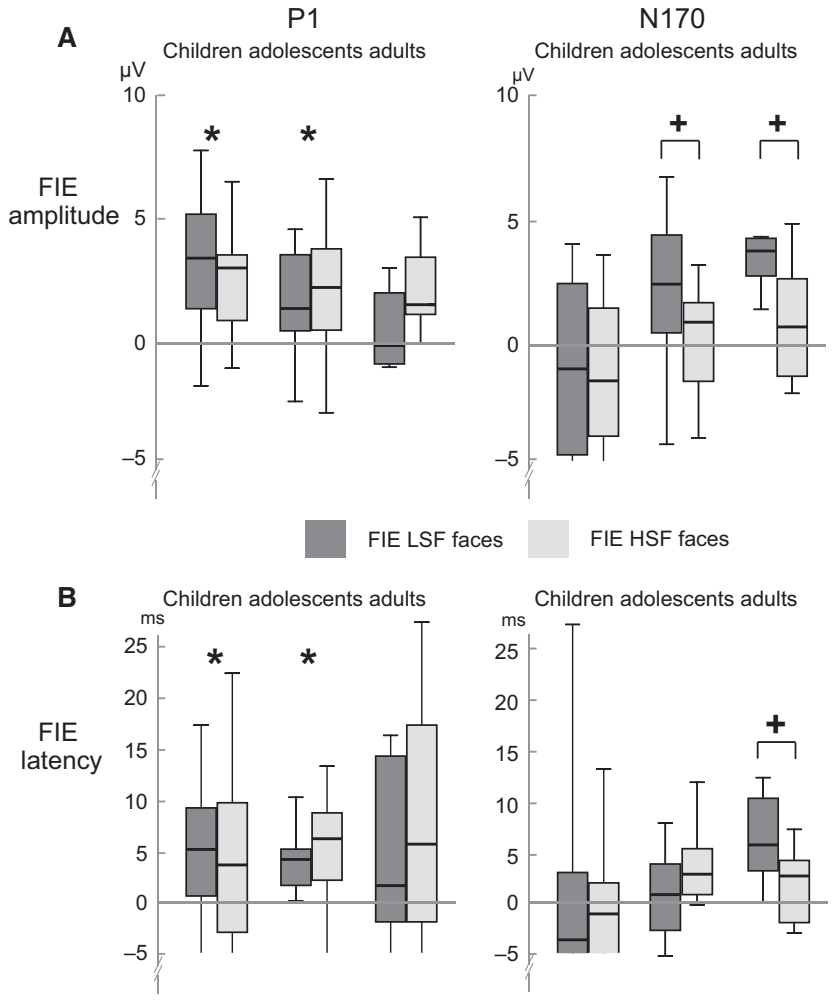

FIG. 6. Boxplots of the median FIE on (A) amplitude and (B) latency of the P1 (left) and N170 (right) averaged across PO7 and PO8. Each box shows the minimum, first quartile, median, third quartile and maximum value. FIE for low-pass (LSF) and high-pass (HSF) filtered faces is computed by subtracting upright from inverted responses, except for N170 amplitude (where inverted is subtracted from upright) to compensate for the negative N170 sign. Asterisks indicate a significant main effect of orientation $(P<0.05)$, whereas plus signs on top of connecting lines indicate a significant interaction between orientation and SF $(P<0.05)$. Note that tests are based on the average of electrode $\mathrm{PO} 7$ and PO8 and can therefore differ from the results in Fig. 5. See also Supporting Information Fig. S12.

$\left(F_{1,9}=5.7, P=0.04, \eta^{2}=0.39\right)$ but which did not interact with other factors.

\section{N170 latency}

There was a significant effect of $\mathrm{SF}\left(F_{2,92}=33.0, P<0.0001\right.$, $\left.\eta^{2}=0.42\right)$. HSF faces elicited an N170 peak with a longer latency than $\operatorname{LSF}\left(t_{48}=7.0, P<0.0001\right)$ and $\operatorname{BSF}\left(t_{48}=7.9, P<0.0001\right)$ faces (Fig. 3). In addition, the interaction between group and orientation was significant $\left(F_{2,46}=4.0, P=0.02, \eta^{2}=0.15\right)$, and group and SF tended to interact $\left(F_{4,92}=2.2, P=0.08, \eta^{2}=0.09\right)$. Further explorations of these interactions revealed main effects of SF in all three groups, and a weak tendency towards an FIE in adolescents $\left(F_{1,18}=3.0, P=0.1, \eta^{2}=0.14\right)$. In adults, the orientation effect was influenced by $\mathrm{SF}\left(F_{2,18}=4.2, P=0.03, \eta^{2}=0.32\right)$. Post hoc tests in adults showed that the expected FIE (i.e. delayed peak for inverted compared with upright faces) was present for BSF $\left(t_{9}=4.3, P=0.02\right)$ and $\operatorname{LSF}\left(t_{9}=5.0, P=0.01\right)$ faces, but not for HSF faces $(P=0.8)$.

Figure 6 shows the neural development of FIEs in more detail. The differential responses elicited by upright and inverted faces (at PO7 and PO8) containing either high or low SF content are plotted per age group. An FIE appears already in early processing stages (P1), but this effect is not influenced by SF content. In the subse- quent processing stage (N170), only adolescents and adults show an FIE. Importantly, this N170 FIE was only present when LSF information was available in the image (i.e. there was an FIE for BSF and LSF but not for HSF faces). Finally, Fig. 7 provides more information on the inter-subject variability per group, which is plotted around the difference waves of the ERPs depicted in Figs 4 and 5. More information about inter-subject variability is also available in the Supporting Information, which provides scatterplots of peak latency and amplitude values per subject (Figs. S1-S12).

\section{Discussion}

The present study investigated the differential role of information in the low vs. high SF ranges in the early stages of facial processing, during childhood, adolescence and adulthood. Results show that the morphology of the P1 and N170 strongly changes across development, as do the cognitive factors influencing them. Importantly, our results show that the FIE occurs in different processing stages for children, adolescents and adults. Moreover, the role of different SF ranges in face processing appears to change during development.

There was a clear change in morphology across the age groups, showing a smaller P1 but more pronounced N170 with increasing age (see also Itier \& Taylor, 2004a). More interestingly, these age effects interacted with our experimental manipulations. On the whole, these interactions confirmed our hypotheses (see Table 1 for an overview).

SF content of faces had a clear effect in all age groups. LSF and BSF faces elicited in general faster and higher P1 and N170 peaks than HSF faces. This effect cannot be driven by low-level stimulus differences, as contrast and luminance were equalized between LSF, BSF and HSF faces. Rather, this effect indicates that facial information in LSF ranges is processed faster than those in HSF ranges, corroborating previous findings in studies using similar stimuli matched for low-level visual features (Vlamings et al., 2010). Neuroimaging studies in adults suggest that LSF content in faces is not only processed faster, but also processed via different neural pathways than HSF content (Vuilleumier et al., 2003; Rotshtein et al., 2007). LSF information travels via the middle occipital gyrus to an area in the fusiform gyrus specialized in face processing (the so-called fusiform face area; Kanwisher et al., 1997), where it converges with HSF information coming from inferior occipital and temporal areas (Rotshtein et al., 2007). Visual processing in newborns is solely based on LSF information (Slater \& Sykes, 1977; de Heering et al., 2007), due to immaturity of the visual system at several levels (reviewed by Ellemberg et al., 2001; Hammarrenger et al., 2003; see also Johnson, 2005). However, although LSF processing is present in newborns, sensitivity for LSF is only fully matured in preadolescence (9-12 years), much later than the maturation of HSF processing at $3-$ 4 years (Adams \& Courage, 2002). Thus, although in young children there is a strong dependence on LSF processing (as also shown by the faster and stronger LSF ERP responses in the present study), the sensitivity to facial cues provided by LSF content might be still rather low during late childhood.

The effect of face inversion strongly differed between age groups. Children only showed an FIE at the earliest stages of processing (i.e. around $100 \mathrm{~ms}$; P1). In contrast, adults only showed an FIE at a later processing stage (around $170 \mathrm{~ms}$; N170). These results corrobarate earlier findings by Itier \& Taylor $(2002,2004 a, b)$ showing a gradual developmental change from early to later FIEs. They (Itier \& Taylor, 2002, 2004c) and others (e.g. Boutsen et al., 2006) suggested that P1 could reflect more holistic face processing (such as detecting global face orientation) whereas the N170 indexes configural processing 

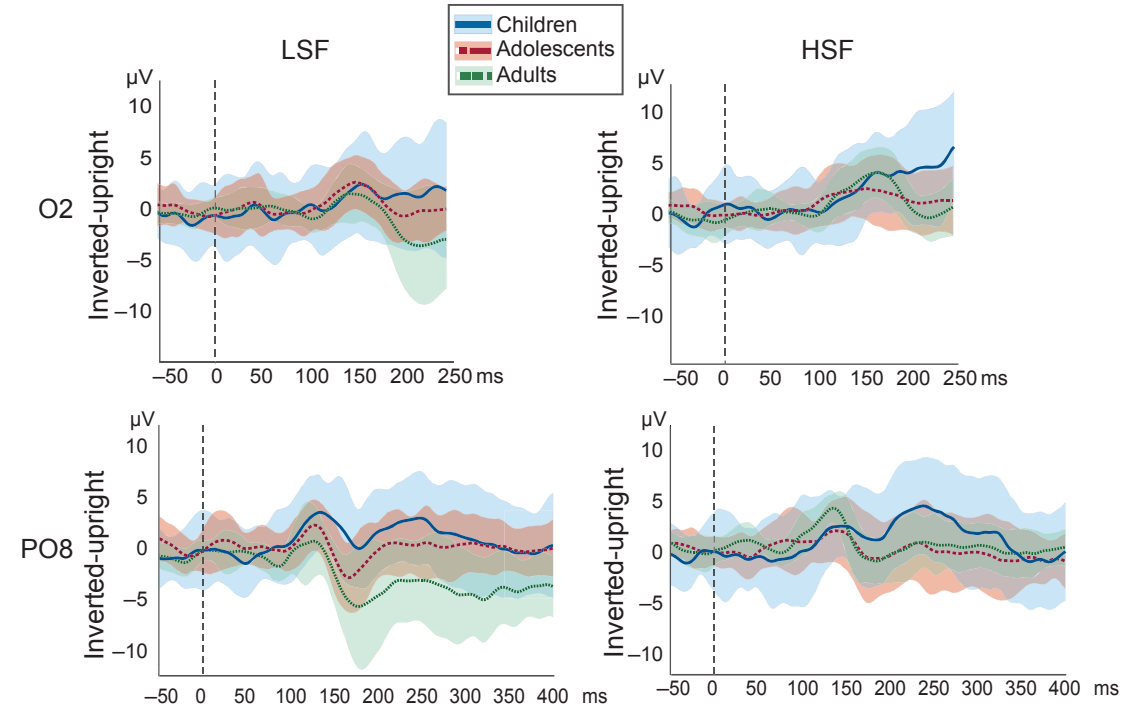

FIG. 7. Difference waves of inverted and upright LSF (left) and HSF (right) faces at O2 (upper row) and PO8 (lower row) per age group (see also Figs 4 and 5). Further conventions as in Fig. 2.

(i.e. relational processing of facial features), two processes that are both disrupted by face inversion. The stronger disruptive effects of inversion on P1 in children and N170 in adults respectively corresponds to behavioural findings suggesting that children use more external features (such as hair) for face recognition (Ellis et al., 1979) and are less skilled in configurational processing (Maurer et al., 2002; Mondloch et al., 2002). The response in adolescents was hybrid, as face inversion affected both the P1 as well as the N170. This is in line with neuroimaging studies showing a progressive growth (Golarai et al., 2007, 2010) and tuning (Passarotti et al., 2007) of the neural face network during adolescence. There is not much known about face processing during this developmental stage, although recent functional magnetic resonance imaging studies revealed that the neural face network of adolescents is still in full development (Passarotti et al., 2007; Peelen et al., 2009; for reviews see Grill-Spector et al., 2008; Cohen-Kadosh \& Johnson, 2007).

Importantly, the FIE was modified by SF content in adolescents and adults, but not in children, which implies that the use of SF content in face processing changes across development. Sergent $(1984,1986)$ was the first to suggest that processing a face based on configural or featural cues depended on information from distinct SF ranges: configural processing depends on LSF information, whereas extraction of face parts is based on HSF. Indeed, several studies have underlined the role of LSF in the fast integration of face features into a united representation and the use of HSF for interpreting face details (e.g. Schyns \& Oliva, 1999; Goffaux et al., 2005; Goffaux \& Rossion, 2006). In adults, N170 amplitude and latency were solely affected by face inversion when LSF information was available in the face stimulus, replicating the results of Goffaux et al. (2003a). This confirms the hypothesis that global information provided by LSF information supports configural face processing, and that configural processing is disrupted by face inversion (e.g. Yin, 1969). Behavioural studies have shown that configural processing develops slowly and is not fully matured in 10-year-olds (e.g. Mondloch et al., 2002). The 9-10-year-old children in our study did not show a differential neural FIE for LSF, BSF or HSF faces, suggesting that the configural processing that mainly depends on LSF information is not fully developed at this age. Interesting complementary findings can be observed for expertise in other object cate- gories than faces: for example, experts can better identify pictures of their object-of-expertise when only LSF information is present (Viggiano et al., 2006), and show a stronger inversion effect (Diamond \& Carey, 1986; Rossion \& Curran, 2010) compared with novices.

Most interestingly, adolescents showed a hybrid pattern: similar to children, they showed FIEs in early (P1) processing stages. However, they also had face-specific modulations in late (N170) processing stages, resembling face processing in adults. This hybrid pattern was also revealed for the role of SF information: the adolescent FIE in the P1 interval was not affected by SF content, matching the results in children. However, similar to adults, the FIE in the N170 period was only present when the faces contained low SF information. Yet, the adolescent N170 appeared not yet to be fully matured, as reflected in the morphology of the N170 (Fig. 2). The N170 shows a bifid morphology in children below 10 (Itier \& Taylor, 2004a). It has been suggested that these two apparent subcomponents seen in children may reflect two different functional sources in temporo-occipital and lateral temporal cortices, which might be involved in more global and configural aspects of face processing, respectively (Itier \& Taylor, 2004a). The change of N170 morphology in adolescence has been related to neural changes in face-selective cortex during this period (Passarotti et al., 2003, 2007). In our study, orientation effects tended to be stronger in the right than left hemisphere for adolescents and adults but not for children (see also Itier \& Taylor, 2004a), which might be related to the right laterized tuning of the fusiform face area during adolescence (Passarotti et al., 2007).

In summary, the present study shows that face perception still undergoes important changes during adolescence. Our ERP findings reveal that more efficient configural face processing skills are acquired during adolescence and that this acquisition depends on the neural maturation of LSF processing in face-selective visual cortex. Children show face-specific effects in early processing stages (i.e. P1 around $100 \mathrm{~ms}$ after stimulus onset), whereas ERPs of adults reveal face-specific effects at a later processing stage (i.e. N170 around $170 \mathrm{~ms}$ ), suggesting a qualitatively different mode of facial analysis. Adolescents show face-specific effects in both processing stages, suggesting a hybrid developmental stage. Importantly, the use of SF content in face processing changes across development. 
Children showed neural FIEs regardless of SF content in faces. In stark contrast, adults only had an FIE when information in the LSF ranges was available. This SF effect is in line with the temporal precedence of the FIE in children compared with adults, as face processing in the P1 interval (linked to processing in early visual cortex; Rossion et al., 1999; Itier \& Taylor, 2002) is suggested to be more superficial than the skilled LSF-dependent configural processing occurring in the N170 period (linked to processing in higher visual cortex; Sagiv \& Bentin, 2001; Rosburg et al., 2009). Most interestingly, adolescents again showed a hybrid pattern: similar to children, the FIE in the P1 interval was not affected by SF content. However, similar to adults, the FIE in the N170 period was only present when the faces contained LSF information. Our results thus suggest that in adolescence, sensitivity to configural cues is developed by increased use of LSF information, which aids the fast and holistic processing that is so special for faces.

Psychophysical developmental studies might encounter non-trivial methodological issues when age ranges are compared on the same task. Differences in task difficulty between age groups often result in floor- and ceiling-effects, distorting developmental effects inferred from behavioural studies (Crookes \& McKone, 2009). This study circumvents such methodological pitfalls in two ways. First, we use an orthogonal attention task (detection of animations) that is unlikely to affect face processing differently across age groups. Secondly, we infer maturation processes from direct neural changes rather than from behavioural results. This might be a better measure for fast, automatic configural processes, as behavioural measures such as face-identification accuracy do not always reflect the degree of holistic processing (Konar et al., 2010). Moreover, we were interested in development of face processing in everyday life, which might be more akin to attentive viewing of faces such as in the present study, compared with the categorization or detection tasks most often used in psychophysics. Face processing is influenced by the task at hand and especially when studying the role of SF in face processing, the influence of the task on the bias to specific SF ranges should be taken into account (Schyns \& Oliva, 1999; Goffaux et al., 2003a; Sowden \& Schyns, 2006). Finally, influencing configural processing by manipulating interattribute distances (e.g. Haig, 1984) makes face stimuli unnatural, which influences face processing strategies (Taschereau-Dumouchel et al., 2010). Instead, we study configural processing by comparing natural faces with their inverted counterparts in the present study. By inverting the face, configural processing is disrupted, while all perceptual input is similar to the upright version - serving as an adequate control in which interattribute distances do not have to be artificially manipulated. Future research could investigate the role of subcortical areas in maturation of LSF-dependent face processing (Johnson, 2005) by applying the present paradigm in a functional magnetic resonance imaging study. In addition, studying how SF availability differentially affects face processing in individuals with a typical development and those with a pervasive developmental disorder might provide more insights into face processing difficulties in autism spectrum disorder, which might be related to specific deficits in LSF processing (Deruelle et al., 2004, 2008; Johnson, 2005; Boeschoten et al., 2007).

\section{Supporting Information}

Additional supporting information can be found in the online version of this article:

Fig. S1. Scatterplot of mean peak latency and amplitude of the P1 on electrode $\mathrm{O} 1$ \& $\mathrm{O} 2$ (left) and of the N170 on electrode PO8 (right) per subject.

Fig. S2. Scatterplot of P1 Latency (left) and Amplitude (right) for low-pass (LSF) and high-pass (HSF) filtered faces on electrode $\mathrm{O} 2$ per subject.

Fig. S3. Scatterplot of N170 Latency (left) and Amplitude (right) for low-pass (LSF) and high-pass (HSF) filtered faces on electrode PO8 per subject.

Fig. S4. Scatterplot of P1 amplitude on electrode O2 for inverted and upright faces that were low-pass (LSF; left) or high-pass (HSF; right) filtered.

Fig. S5. Scatterplot of P1 latency on electrode O2 for inverted and upright faces that were low-pass (LSF; left) or high-pass (HSF; right) filtered.

Fig. S6. Scatterplot of P1 amplitude on electrode PO8 for inverted and upright faces that were low-pass (LSF; left) or high-pass (HSF; right) filtered.

Fig. S7. Scatterplot of P1 latency on electrode PO8 for inverted and upright faces that were low-pass (LSF; left) or high-pass (HSF; right) filtered.

Fig. S8. Scatterplot of N170 amplitude on electrode PO8 for inverted and upright faces that were low-pass (LSF; left) or highpass (HSF; right) filtered.

Fig. S9. Scatterplot of N170 latency on electrode PO8 for inverted and upright faces that were low-pass (LSF; left) or high-pass (HSF; right) filtered.

Fig. S10. Scatterplot of P1 Latency (left) and Amplitude (right) differences for inverted - upright LSF ( $x$-axis) and HSF ( $y$-axis) faces on electrode PO8 per subject.

Fig. S11. Scatterplot of N170 Latency (left) and Amplitude (right) differences for inverted - upright LSF ( $x$-axis) and HSF ( $y$-axis) faces on electrode PO8 per subject.

Fig. S12. Boxplot of P1 and N170 Amplitude (left) and Latency (right) differences for the differential face inversion effect between LSF and HSF (i.e., FIE LSF minus FIE HSF) averaged across PO7 and PO8.

\section{Acknowledgements}

We thank the participants and their parents, and the staff of Basisschool Hulsberg and the Bernard Lievegoed School for their support in participant recruitment. In addition we are grateful to Simone Olrichs and Anita Ham for their help with data acquisition, Valerie Goffaux for help in stimulus creation, and Joel Reithler for comments on the manuscript. This research was supported by NWO (VICI Grant; no. 453-07-004) awarded to C.K.

\section{Abbreviations}

BSF, broad-pass spatial frequency; Cpfw, cycles-per-face-width; EEG, electroencephalogram; ERP, event-related potential; FIE, face inversion effect; HSF, high spatial frequency; LSF, low spatial frequency; SF, spatial frequency.

\section{References}

Achenbach, T.M. (1991) Manual for the Child Behavior Checklist 4-18. University of Vermont, Department of Psychiatry, Burlington, VT.

Adams, J.A. \& Courage, M.L. (2002) Using a single test to measure human contrast sensitivity from early childhood to maturity. Vision Res., 42, 1205 -1210 .

Boeschoten, M.A., Kenemans, J.L., van Engeland, H. \& Kemner, C. (2007) Face processing in Pervasive Developmental Disorder (PDD): the roles of expertise and spatial frequency. J. Neural Transm., 114, 1619-1629. 
Boutsen, L., Humphreys, G.W., Praamstra, P. \& Warbrick, T. (2006) Comparing neural correlates of configural processing in faces and objects: an ERP study of the Thatcher illusion. Neurolmage, 32, 352-367.

Carey, S. \& Diamond, R. (1977) From piecemeal to configurational representation of faces. Science, 195, 312-314.

Cohen-Kadosh, K. (2011) Differing processing abilities for specific face properties in mid-childhood and adulthood. Front. Psychol., 2, 400.

Cohen-Kadosh, K. \& Johnson, M.H. (2007) Developing a cortex specialized for face perception. Trends Cogn. Sci., 11, 267-269.

Costen, N.P., Parker, D.M. \& Craw, I. (1994) Spatial content and spatial quantisation effects in face recognition. Perception, 23, 129-146.

Costen, N.P., Parker, D.M. \& Craw, I. (1996) Effects of high-pass and lowpass spatial filtering on face identification. Percept. Psychophys., 58, 602612

Crookes, K. \& McKone, E. (2009) Early maturity of face recognition: no childhood development of holistic processing, novel face encoding, or face-space. Cognition, 111, 219-247.

De Valois, R.L. \& De Valois, K.K. (1988) Spatial Vision. Oxford University Press, New York.

Deruelle, C., Rondan, C., Gepner, B. \& Tardif, C. (2004) Spatial frequency and face processing in children with autism and Asperger syndrome. J. Autism Dev. Disord., 34, 199-210.

Deruelle, C., Rondan, C., Salle-Collemiche, X., Bastard-Rosset, D. \& Da Fonséca, D. (2008) Attention to low- and high-spatial frequencies in categorizing facial identities, emotions and gender in children with autism. Brain Cognition, 66, 115-123.

Diamond, R. \& Carey, S. (1986) Why faces are and are not special: an effect of expertise. J. Exp. Psychol. Gen., 115, 107-117.

Ellemberg, D., Hammarrenger, F.L., Roy, M. \& Guillemot, J. (2001) Contrast dependency of VEPs as a function of spatial frequency: the parvocellular and magnocellular contributions to human VEPs. Spatial Vision, 15, 99-111.

Ellis, H.D., Shepherd, J.W. \& Davies, G.M. (1979) Identification of familiar and unfamiliar faces from internal and external features: some implications for theories of face recognition. Perception, 8, 431-439.

Farroni, T., Valenza, E., Simion, F. \& Umiltà, C. (2000) Configural processing at birth: evidence for perceptual organisation. Perception, 29, 355372.

Fiorentini, A., Maffei, L. \& Sandini, G. (1983) The role of high spatial frequencies in face perception. Perception, 12, 195-201.

Gaspar, C., Sekuler, A.B. \& Bennett, P.J. (2008) Spatial frequency tuning of upright and inverted face identification. Vision Res., 48, 2817-2826.

Goffaux, V. \& Rossion, B. (2006) Faces are 'spatial'-holistic face perception is supported by low spatial frequencies. J. Exp. Psychol. Hum. Percept. Perform., 32, 1023-1039.

Goffaux, V., Gauthier, I. \& Rossion, B. (2003a) Spatial scale contribution to early visual differences between face and object processing. Brain Res. Cogn. Brain Res., 16, 416-424.

Goffaux, V., Jemel, B., Jacques, C., Rossion, B. \& Schyns, P.G. (2003b) ERP evidence for task modulations on face perceptual processing at different spatial scales. Cognitive Sci., 27, 313-325.

Goffaux, V., Hault, B., Michel, C., Vuong, Q.C. \& Rossion, B. (2005) The respective role of low and high spatial frequencies in supporting configural and featural processing of faces. Perception, 34, 77-86.

Golarai, G., Ghahremani, D.G., Whitfield-Gabrieli, S., Reiss, A., Eberhardt, J.L., Gabrieli, J.D. \& Grill-Spector, K. (2007) Differential development of high-level visual cortex correlates with category-specific recognition memory. Nat. Neurosci., 10, 512-522.

Golarai, G., Liberman, A., Yoon, J.M.D. \& Grill-Spector, K. (2010) Differential development of the ventral visual cortex extends through adolescence. Front. Hum. Neurosci., 3, 80.

Gold, J., Bennett, P.J. \& Sekuler, A.B. (1999) Identification of band-pass filtered letters and faces by human and ideal observers. Vision Res., 39, $3537-3560$.

Gratton, G., Coles, M.G.H. \& Donchin, E. (1983) A new method for offline removal of ocular artefact. Electroen. Clin. Neuro., 55, 468-484.

Grill-Spector, K., Golarai, G. \& Gabrieli, J. (2008) Developmental neuroimaging of the human ventral visual cortex. Trends. Cogn. Sci., 12, 152162.

Haig, N.D. (1984) The effect of feature displacement on face recognition. Perception, 13, 502-512.

Hammarrenger, B., Lepore, F., Lippe, S., Labrosse, M., Guillemot, J.P. \& Roy, M.-S. (2003) Magnocellular and parvocellular developmental course in infants during the first year of life. Doc. Ophthalmol., 107, $225-233$. de Heering, A., Houthuys, S. \& Rossion, B. (2007) Holistic face processing is mature at 4 years of age: evidence from the composite face effect. J. Exp. Child Psychol., 96, 57-70.

Itier, R.J. \& Taylor, M.J. (2002) Inversion and contrast polarity reversal affect both encoding and recognition processes of unfamiliar faces: a repetition study using ERPs. NeuroImage, 152, 353-372.

Itier, R.J. \& Taylor, M.J. (2004a) Face recognition memory and configural processing: a developmental ERP study using upright, inverted, and contrast-reversed faces. J. Cognitive Neurosci., 16, 487-502.

Itier, R.J. \& Taylor, M.J. (2004b) Face inversion and contrast-reversal effects across development: in contrast to the expertise theory. Dev. Sci., 72, 246260.

Itier, R.J. \& Taylor, M.J. (2004c) N170 or N1? Spatiotemporal differences between object and face processing using ERPs. Cereb. Cortex, 14, 132142.

Johnson, M.H. (2005) Subcortical face processing. Nat. Rev. Neurosci., 6, 766-774.

Kanwisher, N., Mc Dermott, J. \& Chun, M.M. (1997) The fusiform face area: a module in human extrastriate cortex specialized for face perception. J. Neurosci., 17, 4302-4311.

Konar, Y., Bennett, P.J. \& Sekuler, A.B. (2010) Holistic processing is not correlated with face-identification accuracy. Psychol. Sci., 21, 3843.

Maurer, D., Le Grand, R. \& Mondlock, C.J. (2002) The many faces of configural processing. Trends Cogn. Sci., 6, 255-260.

Mondloch, C.J., Le Grand, R. \& Maurer, D. (2002) Configural face processing develops more slowly than featural face processing. Perception, 31, 553-566.

Passarotti, A.M., Paul, B.M., Bussiere, J.R., Buxton, R.B., Wong, E.C. \& Stiles, J. (2003) The development of face and location processing: an fMRI study. Dev. Sci., 6, 100-117.

Passarotti, A.M., Smith, J., DeLano, M. \& Huang, J. (2007) Developmental differences in the neural bases of the face inversion effect show progressive tuning of face-selective regions to the upright orientation. NeuroImage, 34, 1708-1722.

Peelen, M.V., Glaser, B., Vuilleumier, P. \& Eliez, S. (2009) Differential development of selectivity for faces and bodies in the fusiform gyrus. Dev. Sci., 12, F16-F25.

Rosburg, T., Ludowig, E., Dumpelmann, M., Alba-Ferrara, L., Urbach, H. \& Elger, C.E. (2009) The effect of face inversion on intracranial and scalp recordings of event-related potentials. Psychophysiology, 47, 147157.

Rossion, B. \& Curran, T. (2010) Visual expertise with pictures of cars correlates with RT magnitude of the car inversion effect. Perception, 39, 173183.

Rossion, B., Delvenne, J.F., Debatisse, D., Goffaux, V., Bruyer, R., Crommelinck, M. \& Guérit, J.M. (1999) Spatio-temporal localization of the face inversion effect: an event-related potentials study. Biol. Psychol., 50, 173-189.

Rotshtein, P., Vuilleumier, P., Winston, J., Driver, J. \& Dolan, R. (2007) Distinct and convergent visual processing of high and low spatial frequency information in faces. Cereb. Cortex, 17, 2713-2724.

Sagiv, N. \& Bentin, S. (2001) Structural encoding of human and schematic faces: holistic and part-based processes. J. Cognitive Neurosci., 13, 937-951.

Schwarzer, G. (2000) Development of face processing: the effect of face inversion. Child Dev., 712, 391-401.

Schyns, P.G. \& Oliva, A. (1999) Dr. Angry and Mr. Smile: when categorization flexibly modifies the perception of faces in rapid visual presentations. Cognition, 69, 243-265.

Sergent, J. (1984) An investigation into component and configural processes underlying facial perception. Brit. J. Psychol., 75, 221-242.

Sergent, J. (1986) Microgenesis of face perception. In Ellis, H.D., Jeeves, M.A., Newcombe, F. \& Young, A.M. (Eds), Aspects of Face Processing. Martinus Nijhoff, Dordrecht, pp. 17-33.

Slater, A. \& Sykes, M. (1977) Newborn infants' visual responses to square wave gratings. Child Dev., 48, 545-554.

Sowden, P.T. \& Schyns, P.G. (2006) Channel surfing in the visual brain. Trends Cogn. Sci., 10, 538-545.

Spreen, O. \& Strauss, E. (1998) A Compendium of Neuropsychological Tests: Administration, Norms and Commentary. Oxford University Press, New York.

Taschereau-Dumouchel, V., Rossion, B., Schyns, P.G. \& Gosselin, F. (2010) Interattribute distances do not represent the identity of real-world faces. Front. Psychol., 1, 159. 
Taylor, M.J., Batty, M. \& Itier, R.J. (2004) The faces of development: a review of early face processing over childhood. J. Cognitive Neurosci., 16, $1426-1442$.

Tottenham, N., Borscheid, A., Ellertsen, K., Marcus, D.J. \& Nelson, C.A. (2002) Categorization of facial expressions in children and adults: establishing a larger stimulus set. Paper presented at the Annual Meeting of the Cognitive Neuroscience Society, San Francisco, CA.

Viggiano, M.P., Righi, S. \& Galli, G. (2006) Category-specific visual recognition as affected by aging and expertise. Arch. Gerontol. Geriat., 42, 329 -338 .

Vlamings, P.H.J.M., Goffaux, V. \& Kemner, C. (2009) Is the early modulation of brain activity by fearful facial expressions primarily mediated by coarse low spatial frequency information? J. Vision, 9, $1-13$.
Vlamings, P.H.J.M., Jonkman, L.M. \& Kemner, C. (2010) An eye for detail: an event-related potential study of the rapid processing of fearful facial expressions in children. Child Dev., 81, 1304-1319.

Vuilleumier, P., Armony, J.L., Driver, J. \& Dolan, R.J. (2003) Distinct spatial frequency sensitivities for processing faces and emotional expressions. Nat. Neurosci., 6, 624-631.

Wechsler, D. (1991) Wechsler Intelligence Scale for Children, 3rd Edn. The Psychological Corporation, San Antonio.

Willenbockel, V., Fiset, D., Chauvin, A., Blais, C., Arguin, M., Tanaka, J.W., Bub, D.N. \& Gosselin, F. (2010) Does face inversion change spatial frequency tuning? J. Exp. Psychol. Hum. Percept. Perform., 36, $122-135$.

Yin, R.K. (1969) Looking at upside-down faces. J. Exp. Psychol., 81, 141145. 